\title{
Case Report: Implantable cardioverter defibrillator (ICD) \\ deactivation in palliative care - a case involving best interest \\ decisions for someone lacking capacity at the end of life
}

\section{[version 1; peer review: 2 approved with reservations]}

\author{
Chevonne Tan11, Sarika Hanchanale², Emma Sugrue², Amara Callistus Nwosu (D) 2-4 \\ ${ }^{1}$ School of Medicine, University of Liverpool, Liverpool, UK \\ ${ }^{2}$ Academic Palliative \& End of Life Care Centre, Liverpool University Hospitals NHS Foundation Trust, Liverpool, UK \\ ${ }^{3}$ International Observatory on End of Life Care, Lancaster University, Lancaster, UK \\ ${ }^{4}$ Marie Curie Hospice Liverpool, Liverpool, UK
}

V1 First published: 21 Jan 2021, 3:4

https://doi.org/10.12688/amrcopenres.12972.1

Latest published: 21 Jan 2021, 3:4

https://doi.org/10.12688/amrcopenres.12972.1

\begin{abstract}
The use of implantable cardioverter-defibrillators (ICD) has increased due to benefits of preventing death from cardiac arrhythmia.

However, the increasing use of ICDs has created new challenges for how to proactively manage deactivation of these devices in people who are dying, especially for those who lack capacity to make decisions about their care. The aim of this case report is to discuss the challenges of planning for deactivation of an ICD for a patient who lacked capacity at the end of life.

We describe the challenges of managing ICD deactivation in a dying patient with fluctuating capacity who had previously expressed a wish for the ICD to remain active. Although it is preferable to use advance care planning $(A C P)$, to provide care in-line with patient-identified care preferences, we demonstrate how a best interest process can be used to make decisions about ICD deactivation at the end of life.
\end{abstract}

Keywords

Palliative care, heart failure, consent, implantable cardioverter defibrillator, resuscitation, capacity, case report

\section{Open Peer Review \\ Approval Status ? ? \\ 2

version 1 ? \\ 21 Jan 2021 \\ view \\ view \\ 1. Suzette Turner (iD), University of Toronto, \\ Toronto, Canada \\ 2. Mark K Elliott ID, King's College London, \\ London, UK}

Any reports and responses or comments on the article can be found at the end of the article. 
Corresponding author: Amara Callistus Nwosu (a.nwosu@lancaster.ac.uk)

Author roles: Tan C: Methodology, Project Administration, Writing - Original Draft Preparation; Hanchanale S: Conceptualization, Project Administration, Supervision, Writing - Original Draft Preparation, Writing - Review \& Editing; Sugrue E: Writing - Review \& Editing; Nwosu AC: Supervision, Writing - Original Draft Preparation, Writing - Review \& Editing

Competing interests: No competing interests were disclosed.

Grant information: This work received no funding. ACN's hospice post is supported by Marie Curie.

The funders had no role in study design, data collection and analysis, decision to publish, or preparation of the manuscript.

Copyright: (c) 2021 Tan C et al. This is an open access article distributed under the terms of the Creative Commons Attribution License, which permits unrestricted use, distribution, and reproduction in any medium, provided the original work is properly cited.

How to cite this article: Tan C, Hanchanale S, Sugrue E and Nwosu AC. Case Report: Implantable cardioverter defibrillator (ICD) deactivation in palliative care - a case involving best interest decisions for someone lacking capacity at the end of life [version 1; peer review: 2 approved with reservations] AMRC Open Research 2021, 3:4 https://doi.org/10.12688/amrcopenres.12972.1

First published: 21 Jan 2021, 3:4 https://doi.org/10.12688/amrcopenres.12972.1 


\section{Introduction}

Over the last couple of decades, the use of implantable cardioverter-defibrillators (ICD) has increased mainly due to benefits of preventing death from cardiac arrhythmia ${ }^{1,2}$. The increasing use of ICDs has provided considerable benefit but has also created new challenges; for example, when people, despite the presence of their implanted device, approach or reach the end of life $^{3}$. ICDs may cause distress for patients and their families at the end of life, as previous studies report that many patients experience shocks from their devices in the dying phase of their illness ${ }^{4}$.

Current guidelines advise that people should be given opportunities to discuss the option of deactivation of their device, particularly at the end of life, with discussion of about the relative benefits and burdens. These discussions should be offered to everyone who is at risk of losing capacity, as well as those with fluctuating capacity ${ }^{5}$. The evidence suggests these conversations rarely happen, with one study reporting that only $35 \%$ of people with an ICD had discussed deactivation before their death ${ }^{6}$. In this case, we provide insight into the challenges of planning for deactivation of an ICD for a patient who lacked capacity at the end of life.

\section{Case report}

Mr X (84 years old, retired, male) was admitted to a hospital specialist palliative care unit in a University teaching hospital in the North West of the UK, for symptomatic management following an admission with a urinary tract infection (UTI) in October 2020. Mr X had a previous history of heart failure, for which an ICD was inserted for management of arrhythmia. He was receiving maximum medical therapy for heart failure and was breathless with increasing frailty. At this point, a clinician explored Mr X's views about ICD deactivation; however, $\mathrm{Mr} \mathrm{X}$ stated that he would like his device to remain active.

Mr X's capacity to make decisions about his care was variable throughout the course of his admission which made advance care planning (ACP) challenging. He developed a hospital acquired pneumonia, became agitated and lost capacity to make decisions about his treatment. We explained our concern that his condition was deteriorating with his family, which resulted in a 'do not attempt cardiopulmonary resuscitation' (DNA-CPR) order being put in place.

Mr X's condition deteriorated further. He was now dying and in the final weeks of his life. However, his ICD was still active and further discussion about deactivation was not possible with him as he now lacked capacity to make decisions about his care. Therefore, we discussed deactivation of his ICD with his family. It was agreed, through a best interest process, that the ICD should be deactivated as the risks of the ICD now outweighed the benefits. The ICD was deactivated by the cardiac physiologists. $\mathrm{Mr} \mathrm{X}$ died a few days later.

\section{Discussion}

Summary

In this case report, we describe the challenges of managing ICD deactivation in a dying patient with fluctuating capacity who had previously expressed a wish for the ICD to remain active.

\section{Strength of article and contribution to the literature}

Our case report provides a real world example of the challenge of managing ICD deactivation at the end of life. We highlight the importance of communication with those important to patients when they lack capacity to make decisions. We identify how a best interest process can be practically used in these situations to help healthcare professionals provide person centred care.

\section{Comparison with previous work}

Consistent with previous studies, our case highlights the challenges of providing care to people with fluctuating capacity caused by advancing illness ${ }^{7-9}$. Specifically, we were unable to re-discuss the issue ICD deactivation with $\mathrm{Mr} \mathrm{X}$ as he became more unwell. Although he had previously stated a preference for his ICD to remain active, we agreed (following discussion with family) that deactivation of the device was in his best interests as the risks harm of the ICD now outweighed the benefits. Our experience is consistent with previous studies, which report how discussions about ICD deactivation rarely take place at the end of life, even if a DNA-CPR order has been completed $^{4,10}$.

Healthcare professionals and patients find these discussions difficult for a number of reasons. Specifically, it is difficult to discuss deactivation of a 'life-saving' device at the time of insertion, and prognostic uncertainty creates challenge to the timing of discussions about deactivation. Furthermore, patients may be resistant to the idea of deactivation of their ICD as they may view a decision to deactivate the device as an indirect decision to end their life.

We were not clear whether $\mathrm{Mr} \mathrm{X}$ was provided the opportunity to discuss developing an ACP earlier in his disease, which would have potentially provided an opportunity to develop a plan to deactivate his ICD as his health declined. Current guidance states that people should receive counselling during and ICD insertion to prepare them for what is involved with the device and future deactivation ${ }^{3}$. When discussion deactivation, healthcare professionals should check the patient's understanding of their ICD, and provide individualised information to the patient $^{3,11}$.

\section{Limitations}

This case describes the experience of one individual, receiving care in a hospital setting during the coronavirus disease 2019 (COVID-19) pandemic; therefore, our experience may not be generalisable.

Implications to policy, practice, and research

Based on our experience, we have identified two recommendations for healthcare professionals who are managing people who are dying with an active ICD. Firstly, we suggest that clinical teams explore ICD deactivation as a patient's clinical condition changes. In hospital, this is important at significant time-points, such as a deterioration in their condition 
and when DNA-CPR decisions are made. Secondly, healthcare professionals should identify patients who have fluctuating capacity, in order to support patients who are able to make advance care plans, and to apply best interest decision making-process for those who lack capacity to make decisions.

\section{Conclusion}

Our case report provides an example of the challenges of managing fluctuating capacity in the presence of an active ICD. Although it is preferable to use ACP to provide care, in-line with patient-identified preferences, we demonstrate how a best interest process can be used to make decisions about ICD deactivation at the end of life.

\section{Data availability}

Underlying data

All data underlying the results are available as part of the article and no additional source data are required

\section{Consent}

Written informed consent for publication of their clinical details was obtained from the relative of the patient.
1. Raatikainen MJP, Arnar DO, Zeppenfeld K, et al.: Statistics on the use of cardiac electronic devices and electrophysiological procedures in the European Society of Cardiology countries: 2014 report from the European Heart Rhythm Association. Europace. 2015; 17 Suppl 1: i1-i75. PubMed Abstract | Publisher Full Text

2. Braunschweig F, Boriani G, Bauer A, et al: Management of patients receiving implantable cardiac defibrillator shocks: recommendations for acute and long-term patient management. Europace. 2010; 12(12): 1673-90. PubMed Abstract | Publisher Full Text

3. Pitcher D, Soar J, Hogg K, et al.: Cardiovascular implanted electronic devices in people towards the end of life, during cardiopulmonary resuscitation and after death: guidance from the Resuscitation Council (UK), British Cardiovascular Society and National Council for Palliative Care. Heart. 2016; 102 Suppl 7: A1-A17. PubMed Abstract | Publisher Full Text

4. Jaarsma $\mathrm{T}$, Beattie JM, Ryder $\mathrm{M}$, et al: Palliative care in heart failure: position statement from the palliative care workshop of the Heart Failure Association of the European Society of Cardiology. Eur J Heart Fail. 2009; 11(5): 433-43.

PubMed Abstract | Publisher Full Text

5. National Institute for Clinical Excellence: Advance care planning for people who may lack capacity to make decisions in future. 2020 Reference Source
6. Stoevelaar R, Brinkman-Stoppelenburg A, van Driel AG, et al.: Trends in time in the management of the implantable cardioverter defibrillator in the last phase of life: a retrospective study of medical records. Eur J Cardiovasc Nurs. 2019; 18(6): 449-57.

PubMed Abstract | Publisher Full Text | Free Full Text

7. Gergel T, Owen GS: Fluctuating capacity and advance decision-making in bipolar affective disorder-self-binding directives and self-determination. Int J Law Psychiatry. 2015; 40: 92-101.

PubMed Abstract | Publisher Full Text | Free Full Text

8. Curtice M: Fluctuating capacity: the concept of micro-and macro-decisions. BJPsych Advances. 2020; 26(4): 238-44. Publisher Full Text

9. Stroup S, Appelbaum P: The subject advocate: protecting the interests of participants with fluctuating decisionmaking capacity. IRB. 2003; 25(3): $9-11$ PubMed Abstract | Publisher Full Text

10. Westerdahl AK, Sjöblom J, Mattiasson AC, et al.: Implantable cardioverterdefibrillator therapy before death: high risk for painful shocks at end of life. Circulation. 2014; 129(4): 422-29. PubMed Abstract | Publisher Full Tex

11. Hupcey JE, Kitko LA: ICD Deactivation at the End of Life: Patient and Caregiver Experiences. J Card Fail. 2013; 19(8): S75-S76. Publisher Full Text 


\section{Open Peer Review}

\section{Current Peer Review Status: ? ?}

Version 1

Reviewer Report 27 January 2022

https://doi.org/10.21956/amrcopenres.14043.r26913

(c) 2022 Elliott M. This is an open access peer review report distributed under the terms of the Creative Commons Attribution License, which permits unrestricted use, distribution, and reproduction in any medium, provided the original work is properly cited.

\section{Mark K Elliott}

School of Biomedical Engineering and Imaging Sciences, King's College London, London, UK

Although a relatively straightforward case, it is always important to highlight end-of-life issues for patients with ICD. There are a few corrections/suggestions outlined below. I also note multiple occasions where the authors state that the use of ICDs has increased 'due to the benefits of preventing death from cardiac arrhythmia'. This statement is unclear. The increasing use of ICDs is arguably more related to improved survival in heart failure and after myocardial infarction, resulting in an increasing population of patients eligible for ICD implant.

Case report section:

"Mr X had a previous history of heart failure, for which an ICD was inserted for management of arrhythmia."

Please state whether this was a primary or secondary prevention device. The purpose of an ICD is to prevent sudden cardiac death - the phrase "management of arrhythmia" is too vague.

Some further detail about the patient's medical history would be helpful:

What were his co-morbidities?

What was the aetiology of his heart failure?

What was his NYHA functional class prior to admission?

Did the patient ever receive therapies from his ICD (shocks / anti-tachycardia pacing).

It would also be useful to appreciate what other decisions were made about his care during this deterioration. Were antibiotics continued? Was any other treatment withdrawn? Was he on an end-of-life care pathway?

"He was now dying and in the final weeks of his life" could be simply replaced with "He was now in 
the final weeks of his life".

Discussion Section:

"We were not clear whether Mr X was provided the opportunity to discuss developing an ACP earlier in his disease, which would have potentially provided an opportunity to develop a plan to deactivate his ICD as his health declined." - This line reads poorly and requires restructuring.

"Current guidance states that people should receive counselling during and ICD insertion to prepare them for what is involved with the device and future deactivation" - counselling should be prior to ICD implant - not 'during' an ICD insertion

"When discussion deactivation, healthcare professionals should check the patient's understanding of their ICD, and provide individualised information to the patient" - correction to "when discussing deactivation..."

"This case describes the experience of one individual, receiving care in a hospital setting during the coronavirus disease 2019 (COVID-19) pandemic; therefore, our experience may not be generalisable." - I'm not sure how COVID affected this case.

Is the background of the case's history and progression described in sufficient detail? No

Are enough details provided of any physical examination and diagnostic tests, treatment given and outcomes?

Partly

Is sufficient discussion included of the importance of the findings and their relevance to future understanding of disease processes, diagnosis or treatment? Yes

Is the case presented with sufficient detail to be useful for other practitioners? Yes

Competing Interests: No competing interests were disclosed.

Reviewer Expertise: Heart failure, cardiac imaging and devices.

I confirm that I have read this submission and believe that I have an appropriate level of expertise to confirm that it is of an acceptable scientific standard, however I have significant reservations, as outlined above.

Reviewer Report 16 September 2021

https://doi.org/10.21956/amrcopenres.14043.r26779 
(C) 2021 Turner S. This is an open access peer review report distributed under the terms of the Creative Commons Attribution License, which permits unrestricted use, distribution, and reproduction in any medium, provided the original work is properly cited.

\section{Suzette Turner}

Schulich Heart Program, Sunnybrook Health Sciences Center, University of Toronto, Toronto, Ontario, Canada

I believe PARTLY due to the need for it to be in the context of palliative care as identified in the title. There are many aspects to palliative care in this case it is in the terminal phase. Overall the case captures the challenges of ICD deactivation therapies especially when capacity issues are forefront. It certainly will be useful to other practitioners. Minor sentence construction also recommended and it should be ready for indexing.

\section{Abstract}

My suggestion is to include palliative care concepts in the abstract.

I believe arrhythmia(s) should be in the plural form throughout the case.

\section{Introduction}

"presence of their implanted device(s)."

\section{Case report}

Instead of maximum medical therapy...consider optimal medical therapy.

Our concerns were expressed while his condition was deteriorating ...instead of starting with "we explained" please start a new sentence with "This resulted in".

Third paragraph: He was now in his final weeks of life (instead of dying and in his final weeks). His ICD therapies remained active and... It was agreed, through a best interest process that the ICD should be deactivated as the alternate of continued shocks from his ICD outweighed the benefits.

\section{Comparison with previous work}

Line 8 sentence needs to be reworked.

\section{Limitations}

I am not sure how COVID pandemic affects deactivation of an ICD.

Is the background of the case's history and progression described in sufficient detail? Partly

Are enough details provided of any physical examination and diagnostic tests, treatment given and outcomes?

Yes

Is sufficient discussion included of the importance of the findings and their relevance to future understanding of disease processes, diagnosis or treatment? 
Yes

Is the case presented with sufficient detail to be useful for other practitioners?

Partly

Competing Interests: No competing interests were disclosed.

Reviewer Expertise: Electrophysiology with a focus on cardiac implantable implantable electronic devices

I confirm that I have read this submission and believe that I have an appropriate level of expertise to confirm that it is of an acceptable scientific standard, however I have significant reservations, as outlined above. 